\title{
Automated Bus Fare Collection System Utilizing Reloadable Radio Frequency Identification (RFID) Card
}

\author{
JO ANNE O. SOCONG \\ jaosocong@universityofboho.edu.ph \\ ORCID No.0000-0002-0269-4419 \\ VICTOR JOHN L. ANUNCIADO \\ vjlanunciado@universityofbohol.edu.ph \\ ORCID No. 0000-0003-4519-4702 \\ LIDUVINA L. NAMOCATCAT \\ IInamocatcat@universityofbohol.edu.ph \\ ORCID No. 0000-0002-6988-9587 \\ RAIZA S. FONGHE \\ raizafonghe@gmail.com \\ ORCID No. 0000-0002-3133-8966
}

MARIAN NICHOLEE B. MIFLORES

marianmiflores@gmail.com

ORCID No. 0000-0003-0874-4197

JAYSON S. LARICAN

Jaysonlarican95@gmail.com

ORCID.ORG/0000-0002-5579-558X

DANIEL BERNALES

Danielbernales93@gmail.com

ORCID No. 0000-0003-3543-8283

JOSHUA A. CORONA

joshuacorona33@gmail.com

ORCID No. 0000-0001-8884-9815 
JOCYRICK R. IBARRA

jhong.ibarra14@gmail.com

ORCID No. 0000-0003-0891-3624

\author{
REYMART C. SORIA \\ soriamart@gmail.com \\ ORCID No. 0000-0002-6341-8434
}

\begin{abstract}
Automated Bus Fare Collection System is a combination of the hardware and software technology and is used in fare collection. The reloadable RFID card used in the system is a small plastic card utilizing Radio Frequency Identification technology for storing information. The system addresses concern of violations and malpractices of conductors, and for the transparency and security of fare collections of the bus companies. This study aimed to develop an automated bus fare collection system for public transportation specifically for buses with Tagbilaran City to Ubay, vice versa, route. It used quantitative-qualitative paradigm for the research design. A survey was conducted to gather the required data. The collected data was then used for data interpretation. Discomfort, inconvenience, and inaccuracy were the three main issues and concerns of the commuters. By using of RFID and GPS, the system collected, recorded and monitored the fare collection with the help of microcontroller Arduino Mega. It had addressed the issues on the discomfort of manual collection of fare, inconvenience on the part of the conductors and passengers whenever there's no change available, and the inaccuracy of fare; for those commuters of Bohol who did not receive the exact amount of change. Thus, this Automated Bus Fare Collection System is recommended.
\end{abstract}

\title{
KEYWORDS
}

Computer Engineering, Automated Bus Fare Collection System, RFID, qualitative, quantitative, weighted mean, chi-square, t-test, transportation, Philippines, Southeast Asia 


\section{INTRODUCTION}

With the advent of modern technology, transportation has to pace up with these demands of the modern times. The masses are now witnessing the impact of technologies and experiencing its benefits in every sector in the community such as in transportation, communication, health, and the like. These advanced technologies give ease and satisfaction to people. In the perspective of traffic, public transit systems are independent of other means of conveyance. The difficult transference of passenger leads to dynamism to have a direct connection to its destination and the need to provide the basic commodity. A study of Tourabi (2002) focuses on the most normal issues why heavy traffics in big cities are present. The infrastructure's importance is being analyzed with mathematical models to have a new or adapted help the transportation planning effective. Keeratiwintakorn (2014) also stated that to avoid delays and accident, the use of vehicle communication in Thailand afford useful information if there are road traffic, car accident, and road construction. Additionally, it also helps to determine traffic calculation, accident warning, and better traffic management for Intelligence Transportation System.

The Automated Fare Collection System is a combination of hardware and software which is used to automate the system collection of fare. It uses smart cards or credit cards that usually work in a vending machine to be able to deduct after there is such transaction happened. This technology was implemented in the Philippines in 2015. The "Beep" reloadable contactless smart card from AF Payments Incorporated and launched last July 20, 2015, to replace the magnetic card-based system. It facilitates payments and serves as a ticket to passengers for the Metro Rail Transit (MRT) and Light Rail Transit (LRT). This "Beep" card can be purchased for 20 Php at the stations or Ticket Vending Machines and can be reloaded from12 Php up to 10,000 Php maximum load (Manila Light Rail Transit System Line 2, 2015).

In Africa, transportation infrastructure is not that expensive and hi-tech than other developing countries. The fare is inappropriate because it is higher than what is expected (Teravaninthorn \& Raballand, 2009). Some cities have large buses which are more expensive than minibusses. In other cities, minibusses are more expensive, and there are cities that the two services have same fares. These variations are caused by fare structures, different routes, bus sizes, private companies, and cities (Bofinger, 2011). 
In some provinces of Luzon, bus transportation is used, but commonly it is used in Visayas and Mindanao regions because rail transits can only be seen in Metro Manila. There are no proper bus stops in Visayas region especially in remote areas, unlike Luzon and Mindanao. In Bohol is one of the provinces in the country that uses a bus as the standard mean of transportation.

Every day, commuters come and go from one town to another through bus or jeepney and within the city are multi-cabs and tricycles. For towns far from Tagbilaran City, the capital of the province, a bus is used as the means of public conveyance, and it is being aided with buses from different bus companies.

The collection of bus fare is manual and risky. The conductor handles cash on hand during the travel, and will also double as the aide to the passengers. Some conductors tend to forget to return the passenger's fare change due to a lot of work they are attending to while in the route that will leave the passengers to ask it from them. Moreover, the fare rate is inconsistent because of the dishonest act of some bus conductors. For that reason, we come up with an ideal solution that would comfort the passenger in their travel and to secure the collection of the bus operating company.

Thus, this research aims to provide convenience to both local and international travelers, to eliminate violations and malpractices of conductors, and for the transparency and security of fare collections of the bus companies. It conveys faster, convenient and systematic transportation services. This issues and concerns are the reason why it is imperative to adopt advanced technology and should be realized through its operation. It further aims to evaluate how automated fare collection using RFID helps to secure the operation of bus transportation. Specifically, it sought to answer the question as to what are the specific issues and concerns which can be addressed by the Automated Bus Fare Collection System Using Reloadable Radio Frequency Identification (RFID) Card for the regular commuters, students, senior citizens, and tourists.

Transportation is the movement of product from a source to a destination. It is the main vitality of the commercial where moving of products is essential. There are various types of transportation; one of this is road-based where motorcycle, bicycle, cars, automobiles, and buses are the most common among them. The modes may depend on the usage of what type of consumer you are. 
Transportation nowadays plays a vital role in economic growth. Economic benefits have a wide range yielded by transportation (Rodrigue et al., 2013). The evolution of transportation from bare human foot to the latest high-end designed means of transportation indicates that the progress and usefulness of technology are essential. In 2015 American Public Transportation Association (APTS) conclude that the public transportation will provide economic opportunities and drives community growth and revitalization.

The fare system in Bohol is a manual type of system that the Conductor wherein does the following step: ask where the passenger started to ride (original location); identify if Student Privilege (SP), a Senior Citizen (SC), Person with Disability (PWD) by presenting their IDs or a regular passenger; ask the passenger's destination (end location); issue a ticket using his stamping device; repeat steps (1-5) until all passengers receive their ticket; confirm if all passengers have their tickets; proceed to collect the fares of each passenger; and give fare change if there is.

All Conductors experience these processes in all buses of Bohol. Moreover, the work of Bus Inspector is to check the ticket booklets of the Conductor if they have issued correctly and precisely the tickets to the passengers.

The AFC is a combination of hardware and software which this technology used to automate the system collection of fare. This technology uses smart cards or credit cards that usually work in a vending machine to be able to deduct after there is such transaction happened.

According to Clarke (1989), the automatic fare ticket collection results from the problem of fare evasion in London Underground. It is known as "Underground ticketing system." In Canada, Cubic Transportation Systems was implemented. Cubic Transportation Systems is the world's driving turnkey arrangement supplier of computerized charge gathering frameworks for open transport including transport, fast transport travel, light rail, suburbanite rail, substantial rail, ship and stopping (Cubic Transportation Systems, 2009). Likewise, "Transport Card" framework has everything that is vital for transportation of residents in the city and encompassing region quoted by (Faculty of Architecture Belgrade University (FABU, 2014).

For the accessibility of the commuters, the passengers have only one card to all the trucking companies, and the commuters do not need different cards for their convenience. The card mostly contains a Radio Frequency Identification (RFID). To have a complete Radio Frequency Identification 
(RFID) system and to acquire the overall benefit of RFID, the system needs an interrogator (reader), a transponder (tag), and an information processing system (IPS). A RFID reader can read many different RFID tags simultaneously as long as the communicating frequencies are within the read range of the reader. The reader serves as the sensor to the RFID system and bridges the RFID tag and the IPS. (Gunda et al., 2015)

A study of Russameesawang and Keeratiwintakorn (2008) states that Global Positioning System (GPS) is a system composing of a network of 24 satellites owned by the United States of America. The first and original purpose of the GPS was to help the military and later on it is allowed to the public for commercial use. The GPS receiver receives the signal from the satellites that periodically emit radio signal of short pulses. These will add features to any project, which tracks the location of the object which has GPS device. GPS satellites calculate distance and use the technique of triangulation to produce its two-dimensional position.

The modern system of Engineering, Accounting, Medical and other field uses online system that leads to automation and easy access to information and application needed. The structural design of the database is consisting of a primary database containing the data from all the transit companies and sub-databases that will store data from each bus transit companies since the system will be used by different transit companies (Isong, B. et al., 2014). Arnold (1988) also stated that innovation that is being produced with state support infers that a country state intentionally uses innovation for force purposes, for instance, the state may help the improvement of a specific innovation that prompts increase of its energy. Therefore, the advancement of the science and innovation turns into an essential concern of all country states. The progression of science, which may bear no course connection to creation, and the improvement of innovation, which speak to the use of science to generation, remain vigorously gathered in the development modern financial matters.

\section{METHODOLOGY}

This study used quantitative paradigm and conducted a survey to collect data from commuters in from and to Tagbilaran City and Municipality of Ubay, vice versa. The respondents were given questionnaires which are the instrument used for the survey. However, a qualitative method was also used to further explain the common scenario of bus accommodation. 
The respondents of this study are the commuters between Tagbilaran City and Municipality of Ubay classified as students, senior citizen, regular and tourist bus commuters. Bus drivers and conductors were also interviewed as key informants about the daily operation of the bus transportation.

The data-gathering used in this study is the survey questionnaire, which is composed of two parts. The demographic questionnaire consists of questions about the respondent's socio-demographic characteristics such as gender, age, civil status, and education. The second part is the survey proper which consists of question regarding the study of the researcher. The survey, which was composed of questions were structured using the Likert format. Four choices were provided for every question or statement. The choices represent the degree of agreement each respondent has on the given question. To collect necessary data for the bus operation and the standard fare rate, data gathering through interview was also done.

This study was conducted at the University of Bohol located at Maria Clara Street, Tagbilaran City, Bohol; Dao Bus Terminal at Dao, Tagbilaran City and Ubay Bus Terminal at Ubay, Bohol but was mainly focused on Tagbilaran to Ubay route.

Data gathered from this study was analyzed using percentages, frequency, and weighted mean. The multivariate analysis utilized chi-square and T-test correlation.

To arrive at a definite, the researcher will assign the following hypothetical mean range to the scales:

Range

$3.25-4.00$

$2.50-3.24$

$1.75-2.49$

$1.00-1.74$
Scale

Strongly Agree

Agree

Disagree

Strongly Disagree 


\section{Process Flow Chart}
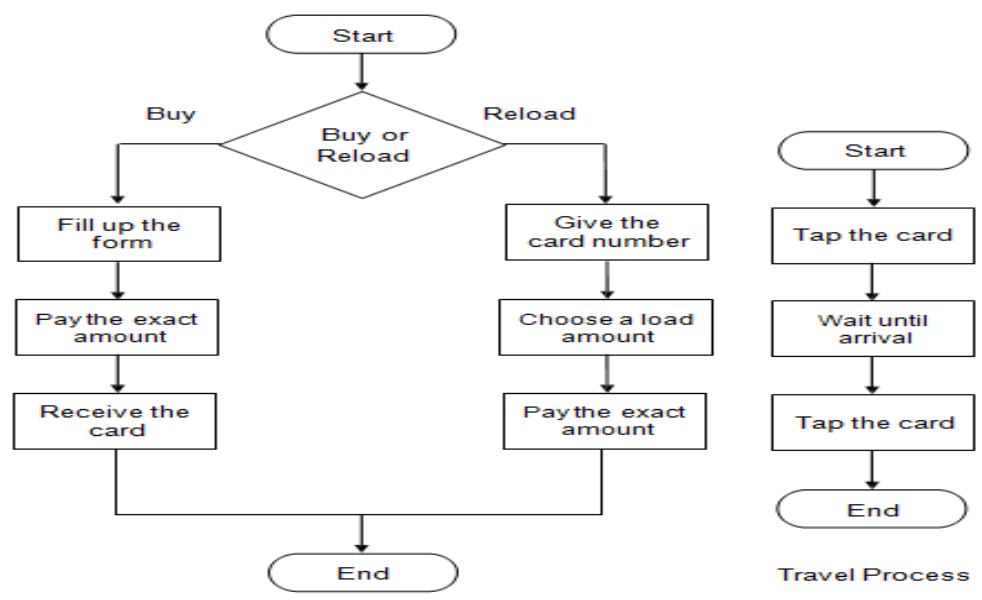

Buy and Reload a Card Process

Figure 2. Automated Bus Fare Collection System Flow Chart

\section{Prototype Development}

1. Microcontroller

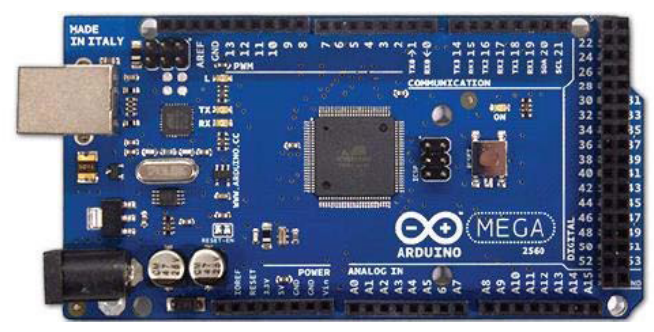

Figure 3.1. Arduino Mega

Arduino Mega functions as the brain of the project which handles data processing including the raw data that the GPS receiver receives from the GPS satellites. 
2. RFID Card and Reader

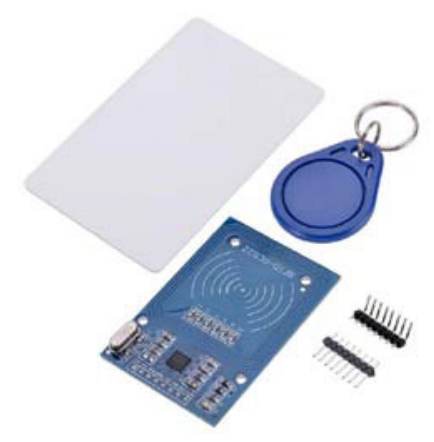

Figure 3.2. RFID module MIFARE RC522 + keychain + keycard (Courtesy of AliExpress)

A tag, reader, and an information processing system, such as a computer, are needed to complete the RFID system section of the Automated Bus Fare Collection System.

3. GPS Receiver

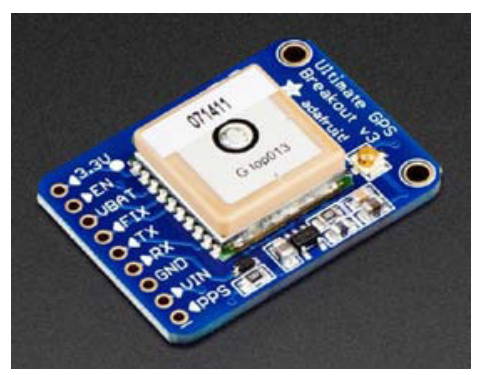

Figure 3.4. Version 3 of Adafruit Ultimate GPS Breakout - 66 channel w/10 Hz updates (Courtesy of Adafruit Industries) 
A GPS receiver will be used in the Automated Bus Fare Collection System in getting the distance traveled.

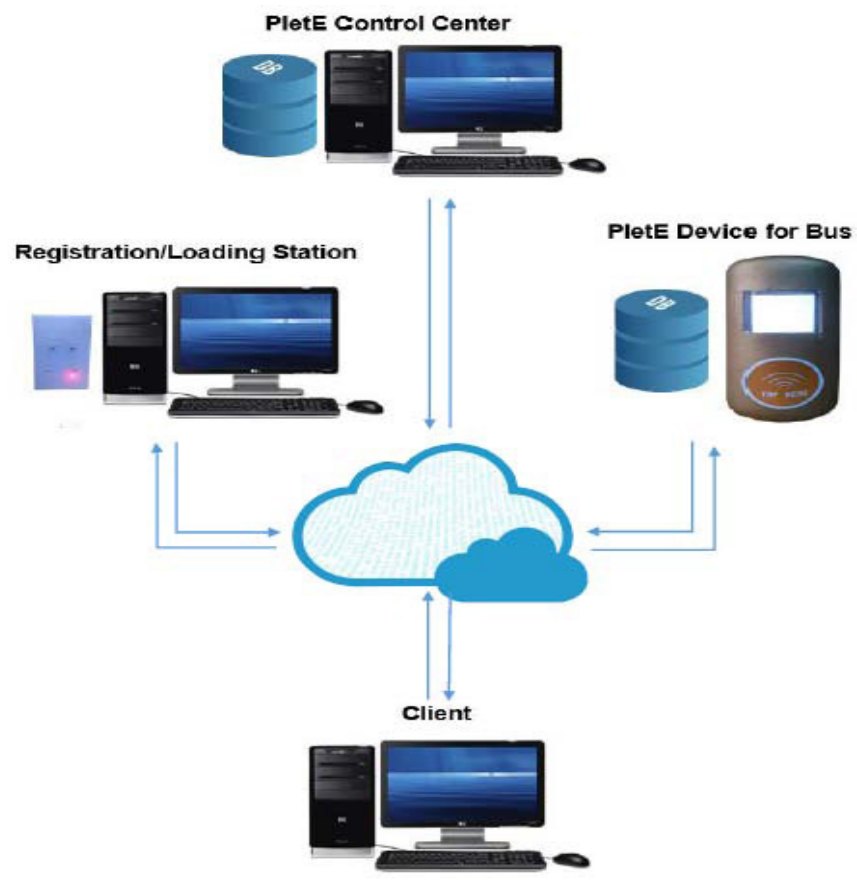

Figure 4. System Diagram

\section{RESULTS AND DISCUSSION}

Table 1. Standard Fare Rate Based from One of the Bus Companies Operating in Bohol

\begin{tabular}{lccc}
\hline ZONE & $\begin{array}{c}\text { KILOMETER 1.10 } \\
\text { php per KM }\end{array}$ & FARE & $\begin{array}{c}\text { SC/SP 20\% } \\
\text { DISCOUNT }\end{array}$ \\
\hline Tagbilaran & 0 & 0 & 0 \\
Baclayon & 8 & 9 & 7.2 \\
Alburquerque & 13 & 14 & 11 \\
Loay & 20 & 22 & 18 \\
Lila & 28 & 31 & 25 \\
\hline
\end{tabular}




\begin{tabular}{lccc}
\hline Dimiao & 35 & 39 & 31 \\
Valencia & 41 & 45 & 36 \\
Garcia Hernandez & 54 & 59 & 47 \\
Jagna & 62 & 68 & 54 \\
Duero & 73 & 73 & 58 \\
Guindulman & 84 & 84 & 67 \\
Candijay & 91 & 91 & 73 \\
Alicia & 103 & 103 & 82 \\
Ubay & 124 & 124 & 99 \\
\hline
\end{tabular}

The table above shows the fare charges from different zones within the Tagbilaran to Ubay route with its corresponding fare rate based from one of the bus companies operating in Bohol. The factors to be considered to measure transportation fare are the distance between the source and the destination, the means of transportation, the size and quantity of the product to be shipped.

The Automated Bus Fare Collection System followed the fare rate mandated by the government which is P8.00 for the first 5 kilometers and additional P1.00 for succeeding kilometers. Through an on-site interview with bus drivers/conductors, it was found out that one of the bus companies in Bohol makes 100 daily trips with their 36 Mazda unit buses that reach all points of destination in the province. With a 60-passenger capacity, a driver and a conductor, their buses accommodate almost 6,000 passengers composing of students, businesspeople, workers, and ordinary passengers from 3:00 a.m. to 9:00 p.m. accordingly.

Table 2. Distribution of Respondents

\begin{tabular}{cccc}
\hline Commuters & $\mathbf{F}$ & $\%$ & $\mathbf{R}$ \\
\hline Student & 70 & $30.43 \%$ & 0.33 \\
Senior citizen & 70 & $30.43 \%$ & 0.33 \\
Regular commuter & 70 & $30.43 \%$ & 0.33 \\
Tourist & 10 & $3.28 \%$ & 2 \\
TOTAL & $\mathbf{2 3 0}$ & $\mathbf{1 0 0 \%}$ & \\
\hline
\end{tabular}


The table 2 describes the distribution of respondents, 230 from commuters consisting 70 students, 70 senior citizens, 70 regular commuters, and 10 tourists, for a total of 230 identified respondents.

\section{Problems Commonly Experienced by Different Group of Commuter}

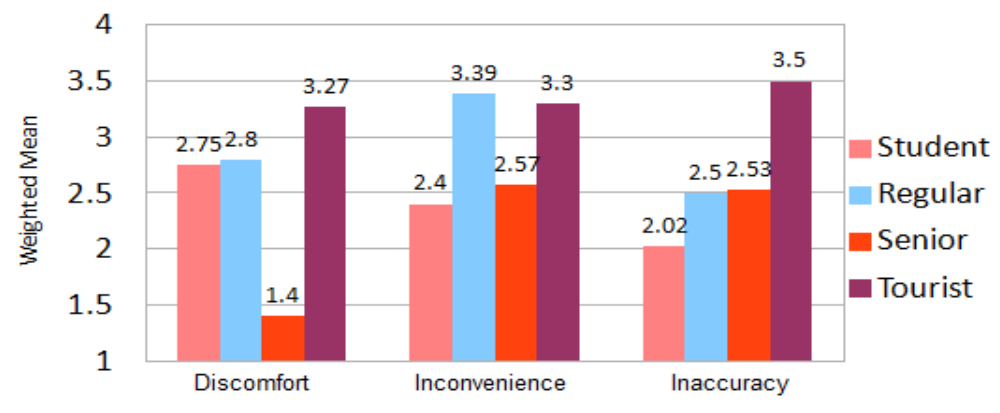

Figure 5. Problems Commonly Experienced by Commuters

There are 212 respondents, classified as a student, senior, tourist, and regular bus passengers of Bohol that were not given the exact amount of change. The ratings are categorized into Strongly Agree, Strongly Disagree, Agree, and Disagree. Using x2-test of independence at 0.05 level of significance.

Table 3. Data Analysis

\begin{tabular}{cccc}
\hline Commuters & Mean & $\begin{array}{c}\text { Standard } \\
\text { Deviation }\end{array}$ & Variance \\
\hline Student & 2.02 & 1.06 & 1.1236 \\
Senior & 2.53 & 1.12 & 1.2544 \\
Tounist & 3.5 & 0.53 & 0.2809 \\
Regular & 2.52 & 1.16 & 1.3456 \\
& Chi-Square x2 = 95.06564609 & \\
& CV of x2 @ 9df \& 0.05 level of significance is 16.919 & \\
& & Result: Significant & \\
& & Decision: Reject H0
\end{tabular}




\section{Table 4. Statics Chi-Square Result}

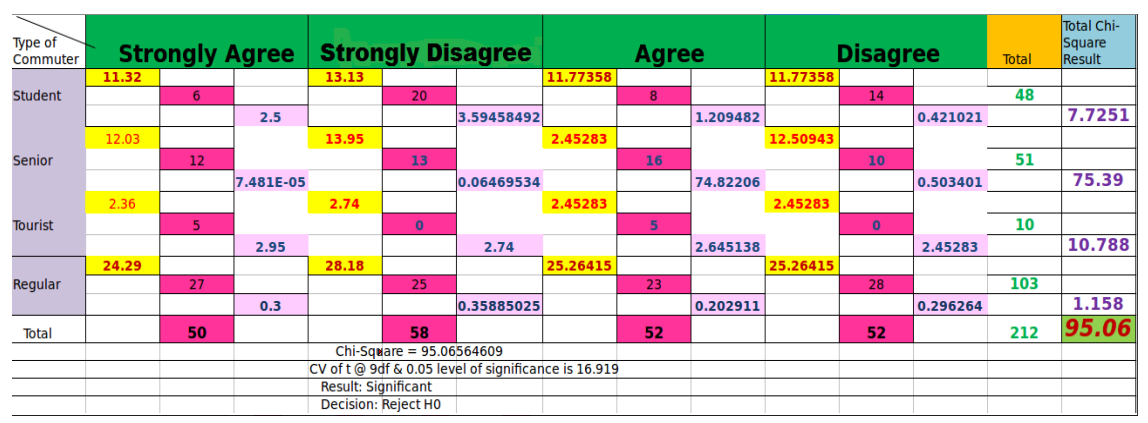

Decision Rule: If the Chi-Square computed value is greater than tabular/ critical value, reject $\mathrm{HO}$.

The computed Chi-Square of 95.06564609 exceeds the critical value of 16.919 at $9 \mathrm{df}$ and significance level of 0.05 thus; the null hypothesis is rejected. The result shows that there is a significant relationship between the students, senior, tourist, and regular bus passenger/commuters of Bohol.

\section{System Testing Using T-Test (Uncorrelated)}

Table 5. Raw Data System Test

\begin{tabular}{ccccc}
\hline No. & Origin & Destination & $\begin{array}{c}\text { Traditional } \\
\text { Fare System }\end{array}$ & $\begin{array}{c}\text { Automated Bus } \\
\text { Fare Collection } \\
\text { System }\end{array}$ \\
\hline 1 & Dao Bus Terminal & Ilaya, Lila & 30 & 28 \\
2 & Dao Bus Terminal & Taug, Lila & 25 & 28 \\
3 & Dao Bus Terminal & Tayong, Loay & 25 & 20 \\
4 & Dao Bus Terminal & Tayong, Loay & 25 & 20 \\
5 & Dao Bus Terminal & Pulang Yuta, Dimiao & 35 & 35 \\
6 & Dao Bus Terminal & Pulang Yuta, Dimiao & 35 & 35 \\
7 & Dao Bus Terminal & Pulang Yuta, Dimiao & 35 & 35 \\
8 & Dao Bus Terminal & Pulang Yuta, Dimiao & 35 & 35 \\
9 & Dao Bus Terminal & Laya, Baclayon & 10 & 9 \\
10 & Dao Bus Terminal & Lomanoy, Lila & 30 & 28 \\
11 & Dao Bus Terminal & Lomanoy, Lila & 30 & 28 \\
12 & Dao Bus Terminal & Lomanoy, Lila & 30 & 28 \\
13 & Dao Bus Terminal & Lomanoy, Lila & 30 & 28 \\
14 & Dao Bus Terminal & Botoc Occ., Loay & 25 & 20 \\
\hline
\end{tabular}




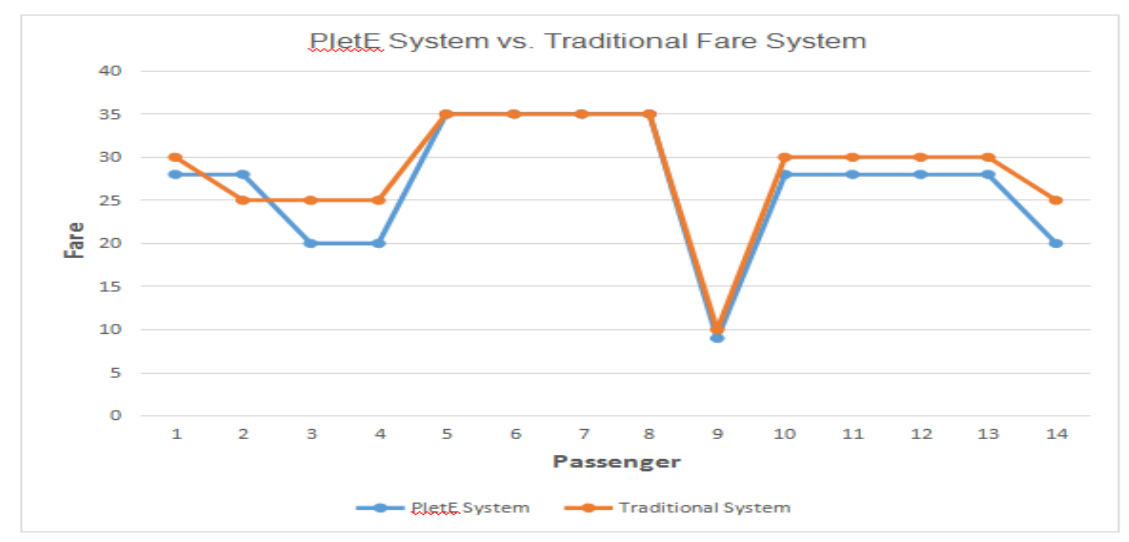

Figure 6. Line Graph of Automated Bus Fare Collection System vs. Traditional Fare System Tabulated Results

Table 6. Statistics

\begin{tabular}{|c|c|c|c|c|c|}
\hline $\mathbf{N}$ & $\begin{array}{l}\text { Traditional } \\
\text { System(X) }\end{array}$ & $\mathbf{X 2}$ & $\mathbf{N}$ & $\begin{array}{l}\text { Automated } \\
\text { Bus } \\
\text { System(Y) }\end{array}$ & Y2 \\
\hline 1 & 30 & 900 & 1 & 28 & 784 \\
\hline 2 & 25 & 625 & 2 & 28 & 784 \\
\hline 3 & 25 & 625 & 3 & 20 & 400 \\
\hline 4 & 25 & 625 & 4 & 20 & 400 \\
\hline 5 & 35 & 1225 & 5 & 35 & 1225 \\
\hline 6 & 35 & 1225 & 6 & 35 & 1225 \\
\hline 7 & 35 & 1225 & 7 & 35 & 1225 \\
\hline 8 & 35 & 1225 & 8 & 35 & 1225 \\
\hline 9 & 10 & 100 & 9 & 9 & 81 \\
\hline 10 & 30 & 900 & 10 & 28 & 784 \\
\hline 11 & 30 & 900 & 11 & 28 & 784 \\
\hline 12 & 30 & 900 & 12 & 28 & 784 \\
\hline 13 & 30 & 900 & 13 & 28 & 784 \\
\hline 14 & 25 & 625 & 14 & 20 & 400 \\
\hline \multirow[t]{3}{*}{$\mathrm{N}=14$} & & $\sum \times 2=12000$ & $\mathrm{~N}=14$ & $\sum Y=377$ & $\sum Y 2=1088$ \\
\hline & $=28.57$ & & & $Y=26.93$ & 5 \\
\hline & CV of t @26 & $\begin{array}{c}\text { Sdf \& } 0.05 \text { lev } \\
\text { Result: Si } \\
\text { Decision: }\end{array}$ & $\begin{array}{l}\text { el of sig } \\
\text { gnifican } \\
\text { Reject } F\end{array}$ & $\begin{array}{l}\text { nificance is } 2 \text {. } \\
0\end{array}$ & 056 \\
\hline
\end{tabular}

Decision Rule: If the t-computed yields a value greater than or beyond the $\mathrm{t}$-tabular/critical value, reject $\mathrm{HO}$. 
The computed t of 2.629 is higher than the critical value of 2.056 at $26 \mathrm{df}$ and 0.05 level of thus, the null hypothesis is rejected. The result shows that there is a significant difference between the fare in Traditional System and the Automated Bus Fare Collection System.

\section{CONCLUSION}

Therefore, the researchers conclude that the tourist commuters are commonly not given the exact amount of change than the other commuters, considering that the mean/average of tourist is 3.50 which is greater compared to the other commuters. Next, to the tourist, regular and senior citizen passengers are also not given an exact amount of change with the average of $2.52 \& 2.53$ respectively. The student has the lowest frequency who were not given an accurate amount of change with the average of 2.02.

It has also been concluded that the Automated Bus Fare Collection System is more accurate than the Traditional System considering that the mean/average of the Automated Bus Fare Collection System of 26.93 is lesser compared to the mean/average score of the Traditional system of only 28.57 .

\section{RECOMMENDATION}

The following are the recommendations of the researchers for future researchers.

\section{Internet Leased Line}

Tunneling or getting a separate Internet connection from the home and regular users will minimize the downtime of the system. It speeds up the connection because the connection has less traffic and much secured for it is a private connection.

\section{Backup Internet Connection}

Availing two internet connections, one from each different telecommunication companies, is a clever decision. If the primary connection is down, the secondary connection kicks in. In this type of connection, system downtime due to no internet connection is much unlikely to happen. 


\section{High Sensitivity GPS Receiver}

The GPS receiver plays a big role in this product. Choose a high sensitivity GPS receiver to get more accuracy. There a lot in the market but the price is quite high.

\section{External GPS Receiver Antenna}

All GPS receiver has a built-in antenna. If the GPS receiver is put inside a box or a metal shield, an external antenna might be needed in some GPS receivers.

\section{Mobile Computer}

In this prototype, we used an Arduino to process the GPS data, a laptop to calculate the distance and to display information. To replace the GPS receiver, laptop, and Arduino and to minimize the cost, we recommend using a smartphone or a tablet that has the following features: (a) GPS capabilities (b) can connect to the internet and (c) has a bigger screen at least 10 inches.

\section{Power Supply}

The prototype draws power directly from the laptop through a USB wire. It is recommended to use external power supply to power up the prototype. A rechargeable 9-volt battery might be an option.

\section{LITERATURE CITED}

Rodrigue, J. P., Comtois, C., \& Slack, B. (2013). The geography of transport systems. Routledge. Retrieved July 29, 2015. From https://goo.gl/ FPACZw

Faculty of Architecture Belgrade University (FABU). (2014, August 29). System for electronic payment of public transport tickets. Belgrade. Serbia. Retrieved September 5, 2015, from http://goo.gl/8KrzhR

Gunda, L., Masuka, L., Nyanga, L., Mhlanga, S., \& Gonye, R. (2012). RFID Based Automatic Tollgate System (RATS). Retrieved August 21, 2015, from https://goo.gl/jyyKVQ

Isong, B., Dominic, E., \& Dzawo, G. (2014, January). On the Automated 
Passengers' Authenticated Bus Transit Services in South Africa. In Proceedings of the International Conference on e-Learning, e-Business, Enterprise Information Systems, and e-Government (EEE) (p. 1). The Steering Committee of the World Congress in Computer Science, Computer Engineering and Applied Computing (WorldComp). Retrieved August 21, 2015, from http://goo.gl/LO3cHC.

Clarke, R. V. (1993). Fare evasion and automatic ticket collection on the London underground. Crime Prevention Studies, 1, 135-146. Retrieved August 9, 2015 from https://goo.gl/quaSZz

Chadil, N., Russameesawang, A., \& Keeratiwintakorn, P. (2008, May). Realtime tracking management system using GPS, GPRS and Google earth. In Electrical Engineering/Electronics, Computer, Telecommunications and Information Technology, 2008. ECTI-CON 2008. 5th International Conference on (Vol. 1, pp. 393-396). IEEE. Last accessed on September 26, 2015. Retrieved from http://goo.gl/wxuJnu.

Manila Light Rail Transit System Line 2. (2015, December 24). Infogalactic: the planetary knowledge core. Retrieved 08:54, July 25, 2017 from https://goo.gl/5DKDDK

Tourabi, K. (2002). Transportation study metropolitan CEBU: a case study [abstract] from https://goo.gl/ADuSRD

Keeratiwintakorn, P. (Jan 02, 2014). Ubiquitous Communication for V2V and V2I for Thailand Intelligent TransportationSystem. Retrieved August 7, 2015 from http://goo.gl/rh07Cc

Teravaninthorn, S., \&Raballand, G. (2009). Transport prices and costs in Africa: a review of the main international corridors. World Bank Publications. Retrieved from https://goo.gl/7HS3do. Last accessed on August 13, 2015.

Arnold, W. (1988). Science and technology development in Taiwan and South Korea. Asian Survey, 28(4), 437-450. from https://goo.gl/ NAQaKT Last accessed on August 13, 2015. 
Bofinger, H., (2011). Africa's Transport Infrastructure: Mainstreaming Maintenance and Management. Washington, DC: The World Bank from https://goo.gl/daqnvz Last accessed on August 12, 2015

Cubic $®$ Transportation Systems, Inc. 09/30/2009. Cubic, TransLink Report Record Use of New Fare Collection System for Canada Line. (n.d.). Retrieved August 13, 2015, from http://goo.gl/xT14qq 